\title{
Novel Type of Chronic Wasting Disease Detected in Moose (Alces alces), Norway
}

\author{
Laura Pirisinu, Linh Tran, Barbara Chiappini, Ilaria Vanni, Michele A. Di Bari, \\ Gabriele Vaccari, Turid Vikøren, Knut Ivar Madslien, Jørn Våge, Terry Spraker, \\ Gordon Mitchell, Aru Balachandran, Thierry Baron, Cristina Casalone, \\ Christer M. Rolandsen, Knut H. Røed, Umberto Agrimi, Romolo Nonno, Sylvie L. Benestad
}

Chronic wasting disease (CWD) persists in cervid populations of North America and in 2016 was detected for the first time in Europe in a wild reindeer in Norway. We report the detection of CWD in 3 moose (Alces alces) in Norway, identified through a large-scale surveillance program. The cases occurred in 13-14-year-old female moose, and we detected an abnormal form of prion protein ( $\mathrm{PrPsc}^{\mathrm{s}}$ ) in the brain but not in lymphoid tissues. Immunohistochemistry revealed that the moose shared the same neuropathologic phenotype, characterized by mostly intraneuronal deposition of $\mathrm{PrPsc}^{\mathrm{s}}$. This pattern differed from that observed in reindeer and has not been previously reported in CWD-infected cervids. Moreover, Western blot revealed a PrPsc type distinguishable from previous CWD cases and from known ruminant prion diseases in Europe, with the possible exception of sheep $\mathrm{CH} 1641$. These findings suggest that these cases in moose represent a novel type of CWD.

$\mathrm{T}$ ransmissible spongiform encephalopathies (TSEs), or prion diseases, are fatal and transmissible neurodegenerative diseases that include scrapie in sheep and goats, bovine spongiform encephalopathy (BSE) in cattle, chronic wasting disease (CWD) in cervids, and CreutzfeldtJakob disease in humans. TSEs are characterized by the

Author affiliations: Istituto Superiore di Sanità, Rome, Italy

(L. Pirisinu, B. Chiappini, I. Vanni, M.A. Di Bari, G. Vaccari,

U. Agrimi, R. Nonno); Norwegian Veterinary Institute, Oslo, Norway (L. Tran, T. Vikøren, K.I. Madslien, J. Våge, S.L.

Benestad); Colorado State University, Fort Collins, Colorado, USA (T. Spraker); Canadian Food Inspection Agency, Ottawa, Ontario, Canada (G. Mitchell, A. Balachandran); Anses Lyon Unité "Maladies Neuro-Dégénératives," Lyon, France (T. Baron); Istituto Zooprofilattico Sperimentale del Piemonte Liguria e Valle d'Aosta, Torino, Italy (C. Casalone); Norwegian Institute for Nature Research, Trondheim, Norway (C.M. Rolandsen); Norwegian University of Life Sciences, Faculty of Veterinary Science, Oslo (K.H. Røed)

DOI: https://doi.org/10.3201/eid2412.180702 misfolding of the normal host-encoded cellular prion protein $\left(\mathrm{PrP}^{\mathrm{C}}\right)$ into an abnormal disease-associated isoform $\left(\mathrm{PrP}^{\mathrm{Sc}}\right)$. $\mathrm{PrPsc}^{\mathrm{Ps}}$ is considered to be the main or exclusive component of prions, the transmissible agents for TSEs (1). TSEs might have a genetic, infectious, or sporadic origin. Classical scrapie and CWD can be highly contagious, spreading directly among animals or through environmental contamination.

Since its first description in Colorado in 1967, CWD has been detected in new geographic areas and with increasing prevalence in captive and free-ranging cervids. Currently, the disease has been diagnosed in 25 states in the United States and in 2 Canada provinces (2,3), along with cases in South Korea associated with importation of infected cervids from Canada (4). High disease prevalence in some areas represents a challenge for preservation of wild cervids and mitigation of human exposure to CWD-related prions $\left(\mathrm{PrPs}^{\mathrm{Sc}}\right)$. The high prevalence might be a plausible explanation for local deer population decline $(5,6)$.

Species naturally affected by CWD include white-tailed deer (Odocoileus virginianus), mule deer (O. hemionus), moose (Alces alces), elk or wapiti (Cervus canadensis), and red deer (C. elaphus). In 2016, CWD was reported for the first time in Europe in wild reindeer (Rangifer tarandus) (7), a species never previously found to be naturally infected. The biochemical analysis and immunohistochemical (IHC) distribution of $\mathrm{PrP}^{\mathrm{Sc}}$ from Norway reindeer revealed a pattern indistinguishable from North America isolates (7).

We report 3 cases of CWD detected in moose in Norway, characterized by biochemical and IHC features clearly different from CWD cases previously described in North America and Norway. Our findings suggest the involvement of a different type of CWD prion.

\section{Materials and Methods}

\section{Animals and Tissues}

The 3 moose were found in Trøndelag County in central Norway. The first case, moose no. 1 (ID P138), was 
emaciated and demonstrated abnormal behavior, showing reduced fear of humans. The second case, moose no. 2 (ID P153), was found dead in a river. Necropsy revealed normal body condition and pregnancy with twins; trauma was the cause of death. The third case, moose no. 3 (ID CD11399), was observed showing abnormal behaviors, including reduced fear of humans. Necropsy revealed a poor body condition and a severe dislocation of the left hip joint, which might have influenced the animal's behavior. All 3 were older female moose $(13,14$, and 13 years old, based on counts of cementum annuli in the root of the first incisor [8]).

Samples included in this study are described in the Table. We performed the primary diagnostic test (TeSeE ELISA; Bio-Rad Laboratories, Inc., Hercules, CA, USA) for detection of protease-resistant core of $\mathrm{PrP}^{\mathrm{Sc}}\left(\mathrm{PrP}^{\mathrm{res}}\right)$ on the 3 moose and 1 reindeer from Norway (7) in the medulla oblongata at the level of the obex. After the initial positive test results, the remaining brain tissues were divided; one half was fixed in $10 \%$ neutral buffered formalin, and the other half was frozen. In addition, lymph nodes (Ln) from moose no. 1 (retropharyngeal, submandibular, and jejunal Ln), moose no. 3 (retropharyngeal, parotid, prescapular, and submandibular Ln, and tonsils), and the reindeer (2 tracheobronchial $\mathrm{Ln}$ ) were equally divided and formalin fixed or frozen.

\section{Genotyping of Moose PRNP}

DNA was extracted from $100 \mathrm{mg}$ of brain tissue by using a DNeasy Blood and Tissue Kit (QIAGEN, Hilden, Germany), according to the manufacturer's instructions. The PRNP coding sequence was amplified in a $50 \mu \mathrm{L} \mathrm{fi-}$ nal volume by using $5 \mu \mathrm{L}$ of extracted DNA, eluate $1 \mathrm{X}$
AmpliTaq Gold 360 PCR Buffer (Life Technologies, Carlsbad, CA, USA), $2.5 \mathrm{mmol} / \mathrm{L} \mathrm{MgCl}_{2}, 1 \mathrm{X} 360 \mathrm{GC}$ Enhancer (Life Technologies), $200 \mu \mathrm{mol} / \mathrm{L}$ dNTPs, 0.25 $\mu \mathrm{mol} / \mathrm{L}$ of forward $\left(5^{\prime}\right.$-GCTGACACCCTCTTTATTTTGCAG-3') and reverse (5'-GATTAAGAAGATAATGAAAACAGGAAG - $3^{\prime}$ ) primers (11), and $0.5 \mu \mathrm{L}$ AmpliTaq Gold 360 (Life Technologies), according to the following amplification protocol: $5 \mathrm{~min}$ at $96^{\circ} \mathrm{C} ; 30 \mathrm{~s}$ at $96^{\circ} \mathrm{C} ; 15 \mathrm{~s}$ at $57^{\circ} \mathrm{C} ; 90 \mathrm{~s}$ at $72^{\circ} \mathrm{C}$ for 40 cycles; and $4 \mathrm{~min}$ at $72^{\circ} \mathrm{C}$. Amplicons were purified with the Illustra ExoProStar 1-Step clean-up kit (GE Healthcare Life Sciences, Little Chalfont, UK), sequenced using the Big Dye Terminator Cycle Sequencing Kit v1.1 (Life Technologies), and purified with the Big Dye XTerminator Purification Kit (Life Technologies), and detected by using an ABI PRISM 3130 apparatus (Life Technologies).

\section{Anti-Prion Protein Monoclonal Antibodies}

Several antibodies with different epitopes (sheep prion protein $[\mathrm{PrP}]$ numbering) were used for discriminatory Western blot (WB) and IHC. SAF84 (aa 167-173) was obtained from Bertin Pharma (Montigny-le-Bretonneux, France), L42 (aa 148-153) from R-Biopharm (Darmstadt, Germany), 9A2 (aa 102-104) and 12B2 (aa 93-97) from Wageningen Bioveterinary Research (Lelystad, Netherlands), and F99/97.6 (aa 220-225) from VMRD, Inc. (Pullman, WA, USA).

\section{Immunohistochemistry}

Brain, Ln, and tonsil tissues were formalin fixed for $\geq 48 \mathrm{~h}$ and processed by standard histopathologic techniques. We used IHC to visualize the distribution of $\mathrm{PrP}^{\mathrm{Sc}}$ as previously described (7). We applied a commercially available kit

\begin{tabular}{|c|c|c|c|c|}
\hline Animal or species & Geographic origin & Age & Pathologic phenotype & PrP genotype $\dagger$ \\
\hline Moose no. 1 & Norway & $13 y$ & Atypical CWD & $\mathrm{KK}_{109} \mathrm{MM}_{209}$ \\
\hline Moose no. 2 & Norway & $14 \mathrm{y}$ & Atypical CWD & $\mathrm{KK}_{109} \mathrm{MM}_{209}$ \\
\hline Moose no. 3 & Norway & $13 y$ & Atypical CWD & $\mathrm{KK}_{109} \mathrm{MM}_{209}$ \\
\hline Reindeer & Norway & $3-4 y$ & CWD & $\mathrm{VV}_{2} \mathrm{GG}_{129} \mathrm{SS}_{138} \mathrm{VV}_{169}$ \\
\hline Elk or wapiti & Canada & $6 y$ & CWD & $\mathrm{MM}_{132}$ \\
\hline Elk or wapiti & Canada & Adult & CWD & $\mathrm{MM}_{132}$ \\
\hline Elk or wapiti & Canada & $6 y$ & CWD & $\mathrm{MM}_{132}$ \\
\hline White-tailed deer & Canada & $4 y$ & CWD & $\mathrm{GG}_{96}$ \\
\hline Moose & Canada & Adult & CWD & $\mathrm{KK}_{109} \mathrm{I}_{209} \ddagger$ \\
\hline Sheep & Italy & $2.5 \mathrm{y}$ & Classical scrapie & $\mathrm{AA}_{136} \mathrm{RR}_{154} \mathrm{QQ}_{171}$ \\
\hline Sheep & Italy & Adult & Classical scrapie & $\mathrm{AA}_{136} \mathrm{RR}_{154} \mathrm{QQ}_{171}$ \\
\hline Sheep & Italy & $4.5 \mathrm{y}$ & Atypical/Nor98 scrapie & $\mathrm{AA}_{136} \mathrm{RH}_{154} \mathrm{QQ}_{171}$ \\
\hline Sheep & Experimental sample & NA & Scrapie CH1641§ & $\mathrm{AA}_{136} \mathrm{HH}_{154} \mathrm{QQ}_{171}$ \\
\hline Sheep & France & NA & Scrapie CH1641-likeף & $\mathrm{AA}_{136} \mathrm{RR}_{154} \mathrm{QQ}_{171}$ \\
\hline Cattle & Italy & $6 y$ & C-BSE & NA \\
\hline Cattle & Italy & $15 y$ & L-BSE & NA \\
\hline Cattle & France & $11 \mathrm{y}$ & H-BSE & NA \\
\hline \multicolumn{5}{|c|}{$\begin{array}{l}\text { *All samples were from naturally infected animals, with the exception of } 1 \text { sheep experimentally inoculated with CH1641. BSE, bovine spongiform } \\
\text { encephalopathy; C-BSE, classical BSE; CWD, chronic wasting disease; H-BSE, H-type atypical BSE; L-BSE, L-type atypical BSE; NA, not available; PrP, } \\
\text { prion protein. } \\
\text { †The PrP genotype reported is expressing the amino acid variants present at the major polymorphic codons described for each species. } \\
\left.\text { fThe Canada isolate was homozygous for lysine at codon } 109 \text { and for isoleucine at codon } 209 \text { (KK } 109 l_{209}\right) \text { (GenBank accession no. MH230114). } \\
\text { §Reference }(9) \text {. } \\
\text { TReference (10). }\end{array}$} \\
\hline
\end{tabular}


(EnVisionTM + System HRP [(AEC)] DAKO, Glostrup, Denmark) by using the monoclonal antibodies (mAbs) 12B2, 9A2, L42, SAF 84, or F99/97.6 for 30 min at $37^{\circ} \mathrm{C}$ and counterstained with hematoxylin. In each run, tissues from CWD-negative moose and reindeer were added as negative controls.

\section{PrPres Detection}

We initially tested the obex samples by using the TeSeE SAP ELISA and confirmed positive ELISA results by using the TeSeE WB. Both tests were performed as recommended by the manufacturer (Bio-Rad).

\section{Typing of PrPres}

We performed further characterization of $\mathrm{PrP}^{\mathrm{res}}$ by discriminatory immunoblotting, according to the ISS discriminatory WB method (12). Brain homogenates at 10\% (wt/vol) in $100 \mathrm{mmol} / \mathrm{L}$ Tris- $\mathrm{HCl}(\mathrm{pH} 7.4) 2 \%$ sarkosyl were incubated for $1 \mathrm{~h}$ at $37^{\circ} \mathrm{C}$ with Proteinase K (Sigma-Aldrich, St. Louis, Missouri, USA) to a final concentration of 200 $\mu \mathrm{g} / \mathrm{mL}$. Protease treatment was stopped with $3 \mathrm{mmol} / \mathrm{L}$ PMSF (Sigma-Aldrich). Aliquots of samples were added with an equal volume of isopropanol/butanol (1:1 vol/vol) and centrifuged at $20,000 \times g$ for $10 \mathrm{~min}$. The pellets were resuspended in denaturing sample buffer (NuPAGE LDS Sample Buffer; Life Technologies) and heated for $10 \mathrm{~min}$ at $90^{\circ} \mathrm{C}$.

We loaded each sample onto $12 \%$ bis-Tris polyacrylamide gels (Invitrogen) for electrophoresis with subsequent WB on polyvinylidene fluoride membranes using the Trans-Blot Turbo Transfer System (Bio-Rad) according to the manufacturer's instructions. The blots were processed with anti-PrP mAbs by using the SNAP i.d. 2.0 system (Millipore, Burlington, MA, USA) according to the manufacturer's instructions. After incubation with horseradish peroxidase-conjugated anti-mouse immunoglobulin (Pierce Biotechnology, Waltham, MA, USA) at 1:20,000, the PrP bands were detected by using enhanced chemiluminescent substrate (SuperSignal Femto; Pierce Biotechnology) and ChemiDoc imaging system (Bio-Rad). The chemiluminescence signal was quantified by using Image Lab 5.2.1 (Bio-Rad).

We performed deglycosylation by adding $18 \mu \mathrm{L}$ of 0.2 $\mathrm{mmol} / \mathrm{L}$ sodium phosphate buffer ( $\mathrm{pH} 7.4$ ) containing $0.8 \%$ Nonidet P40 (Roche) and $2 \mu \mathrm{L}(80 \mathrm{U} / \mathrm{ml})$ di N-Glycosidase $\mathrm{F}$ (Roche) to $5 \mu \mathrm{L}$ of proteinase $\mathrm{K}$-digested and denaturated samples. We then incubated the mixtures for $3 \mathrm{~h}$ at $37^{\circ} \mathrm{C}$ with gentle shaking.

\section{Results}

CWD was diagnosed in 2 moose in May 2016 in Norway's Selbu municipality and in 1 moose in October 2017 in Lierne municipality. Selbu and Lierne are respectively located $\approx 300$ and $\approx 450 \mathrm{~km}$ northeast of Nordfjella, where CWD in reindeer was detected in 2016. Norway is populated by several species of wild cervids with varying degrees of overlapping range. Seasonal migrations are common and distances might exceed $150 \mathrm{~km}(13-15)$. However, studies tracking global positioning satellitecollared moose have not documented regular seasonal migrations between Selbu and Lierne municipalities, suggesting that these can be considered different moose subpopulations.

We initially detected $\mathrm{PrP}^{\mathrm{Sc}}$ in brain samples by using a rapid test and then confirmed by WB (data not shown) and IHC. Sequencing analysis of the entire PrP coding sequence revealed that the 3 moose had the wild type PrP genotype, homozygous for lysine at codon 109 and for methionine at codon $209\left(\mathrm{KK}_{109} \mathrm{MM}_{209}\right)(\mathrm{GenBank}$ accession no. MH230115).

\section{Discriminatory PrPs Immunohistochemistry Show Differences between Reindeer and Moose}

The distribution of $\mathrm{PrP}^{\mathrm{Sc}}$ staining was examined by IHC and compared in the tissues of the 3 moose and the reindeer by using 5 different antibodies (Figure 1). No staining was observed in CWD-negative reindeer and moose independently of the antibody used. The distribution of $\mathrm{PrP}^{\mathrm{Sc}}$ in the reindeer was identical for each of the 5 antibodies and did not differ from the description of $\mathrm{PrP}^{\mathrm{Sc}}$ distribution in North America cervids (16-18). The labeling was most consistent within the gray matter of the medulla oblongata, particularly in the dorsal motor of the vagus nerve (7). The thalamic and brain stem regions of the brain were most affected, with a minimal amount of $\mathrm{PrP}^{\mathrm{Sc}}$ identified dorsal to the corpus callosum.

$\mathrm{PrP}^{\mathrm{Sc}}$ labeling in the moose brains (Figure 1, panels F-J) was clearly different from that of the reindeer (Figure 1, panels A-E). In the moose, after staining with F99/97.6 and L42, $\mathrm{PrP}^{\mathrm{Sc}}$ was almost exclusively observed as intraneuronal aggregates, although intraastrocytic type (multiple small granules scattered in the cytoplasm of astrocyteresembling cells) and intramicroglial type (1 single or a few large granules in close proximity to microglia-like nuclei) were also observed in the cerebral cortices and olfactory bulb (online Technical Appendix Figure 1, panel A, https://wwwnc.cdc.gov/EID/article/24/12/18-0702Techapp1.pdf). The degree of $\mathrm{PrP}^{\mathrm{Sc}}$ staining was more intensive and appeared more widespread in the neuropil using SAF84.

At the level of the obex, we found stained neurons in all nuclei, whereas the dorsal motor of the vagus nerve was not remarkably stained, as observed in reindeer. The intensity of labeling varied among the 3 moose; no. 2 displayed sparse labeling, no. 3 widespread and abundant labeling, and no. 1 intermediate labeling intensity. We observed $\mathrm{PrP}^{\mathrm{Sc}}$ in all parts of the brain investigated except the 


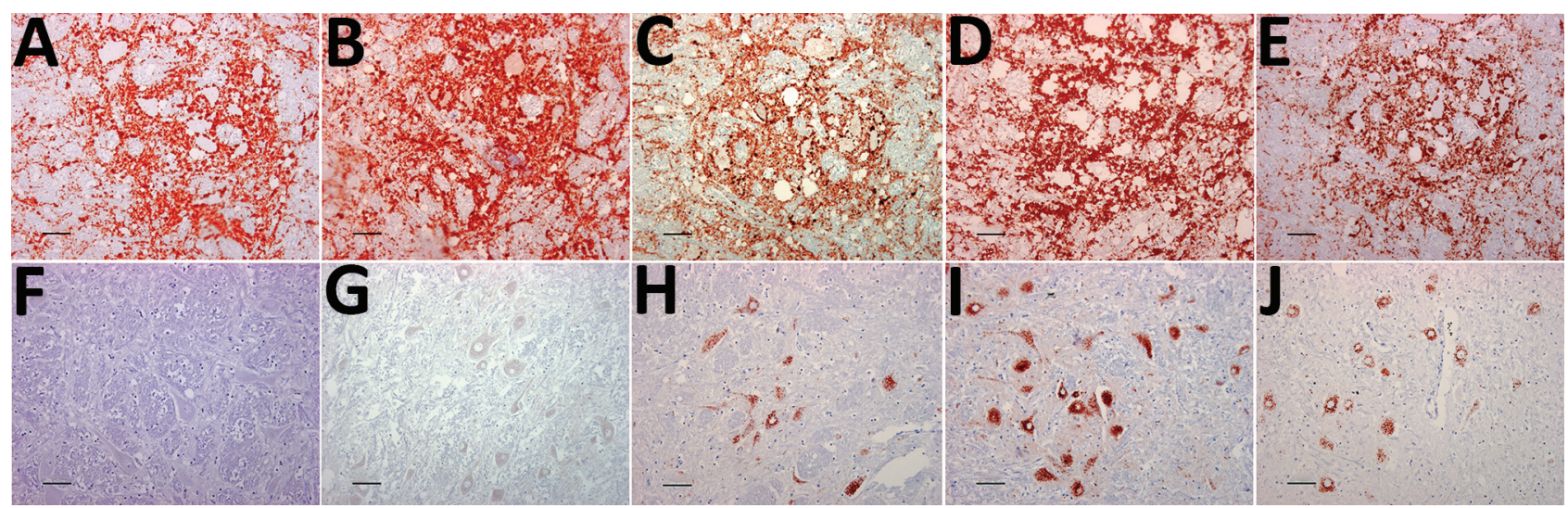

Figure 1. Immunohistochemical detection of disease-associated prion protein in brain sections at the level of the obex in cervids with chronic wasting disease, Norway. A-E) Reindeer; F-J) moose. mAbs used were 12B2 (A, F), $9 A 2$ (B, G), L42 (C, H), SAF 84 (D, I), and F99/97.6 (E, J). Staining obtained in the reindeer tissues is similar regardless of mAbs used (A-E). Conversely, for moose tissues, the staining was primarily observed intraneuronally with L42, SAF84, and F99/97.6 (H-J) but was not observed using the more $\mathrm{N}$-terminal mAbs $12 B 2$ and 9A2 (F, G). Scale bars indicate $40 \mu \mathrm{m}$. mAbs, monoclonal antibodies.

cerebella of moose nos. 1 and 2. A diffuse or discrete punctate staining was observed in the granular layer of the cerebellum of moose no. 3, with stronger staining in some Golgi neurons (online Technical Appendix Figure 1, panel B). In all 3 moose, the cortical regions showed laminar staining of neurons in all the cell layers, especially in fusiform-shaped neurons. The neurons of the olfactory tubercle from all 3 also stained strongly, and some gliaassociated staining could be observed.

In contrast to the reindeer, the downstream flexible tail mAbs $12 \mathrm{~B} 2$ and 9A2 did not stain in the moose (Figure 1 , panels $\mathrm{F}$ and $\mathrm{G}$ ), suggesting that the moose $\mathrm{PrP}^{\mathrm{Sc}}$ was truncated by endogenous proteases further upstream in the $\mathrm{N}$ terminus than was reindeer $\operatorname{PrP}^{\mathrm{Pc}}$. Contrary to previous findings in reindeer, $\mathrm{PrP}^{\mathrm{Sc}}$ was not detected in the $\mathrm{Ln}$ from moose no. 1 or in the Ln and tonsils from moose no. 3 (lymphoid tissues were not available in moose no. 2) by either IHC or ELISA.

\section{PrPsc from Norway Moose Compared with Other CWD Isolates from Canada and Norway}

We compared the $\mathrm{PrP}^{\mathrm{Sc}}$ features in moose from Norway with those of other CWD isolates from Norway and Canada by discriminatory WB, which enabled comparison of $\mathrm{PrP}^{\mathrm{res}}$ by epitope mapping with different antibodies. Norway moose $\mathrm{PrP}^{\mathrm{res}}$ had a lower apparent molecular weight (MW) than $\mathrm{PrP}^{\mathrm{res}}$ from Norway reindeer (Figure 2, panel A) or from Canada isolates (Figure 2, panel B). This lower MW was explained by the occurrence of more $\mathrm{C}$-terminal cleavage of $\mathrm{PrP}^{\mathrm{Sc}}$ by protease $\mathrm{K}$, as confirmed by the partial loss of the 12B2 epitope (Figure 2, panel B).

Given the unusual pattern observed in moose isolates from Norway, we further investigated their biochemical characteristics with additional mAbs and by enzymatic deglycosylation (Figure 3). Moose samples showed a main C-terminal fragment of $\approx 17 \mathrm{kDa}$, detected with SAF84, L42, and 9A2, and an additional glycosylated C-terminal fragment of $\approx 13 \mathrm{kDa}$ (CTF13) detected only with SAF84. The $\mathrm{N}$ terminal 12B2 epitope was mainly lost, although a small amount of PrPres was still detectable in moose no. 1 (Figure 3) and no. 3 (online Technical Appendix Figure 2) with this antibody.
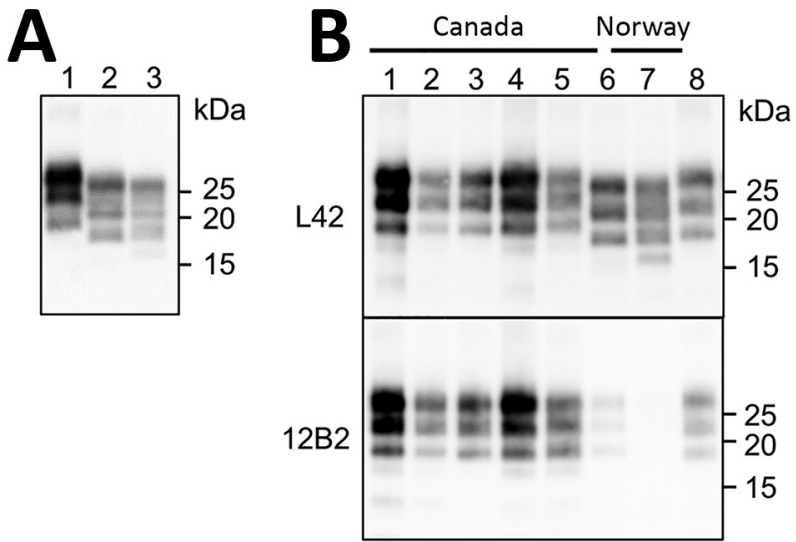

Figure 2. Western blot analysis of PrPres in brains of chronic wasting disease-affected cervids from Norway and Canada. A) Western blot analysis PrPres in brains of moose and reindeer from Norway. Membrane was probed with L42 monoclonal antibodies. Molecular weights $(\mathrm{kDa})$ are indicated on the right. Tissue equivalent loaded per lane was $1 \mathrm{mg}$. B) Western blot analysis of PrPres from moose isolates from Norway (lanes 6-7) compared with PrPres from chronic wasting disease-affected elk or wapiti (lanes 1-3), white-tailed deer (lane 4), and moose (lane 5) from Canada. Membranes were probed with L42 (upper) and 12B2 (lower) monoclonal antibodies. A scrapie sheep sample from Italy was added as control (lane 8). Molecular weights (kDa) are indicated on the right of each blot. Tissue equivalents loaded per lane were $1 \mathrm{mg}$ for Canadian isolates, $2 \mathrm{mg}$ for Norwegian isolates, and $0.15 \mathrm{mg}$ for scrapie sheep control. PrPres, proteaseresistant core of abnormal form of prion protein. 

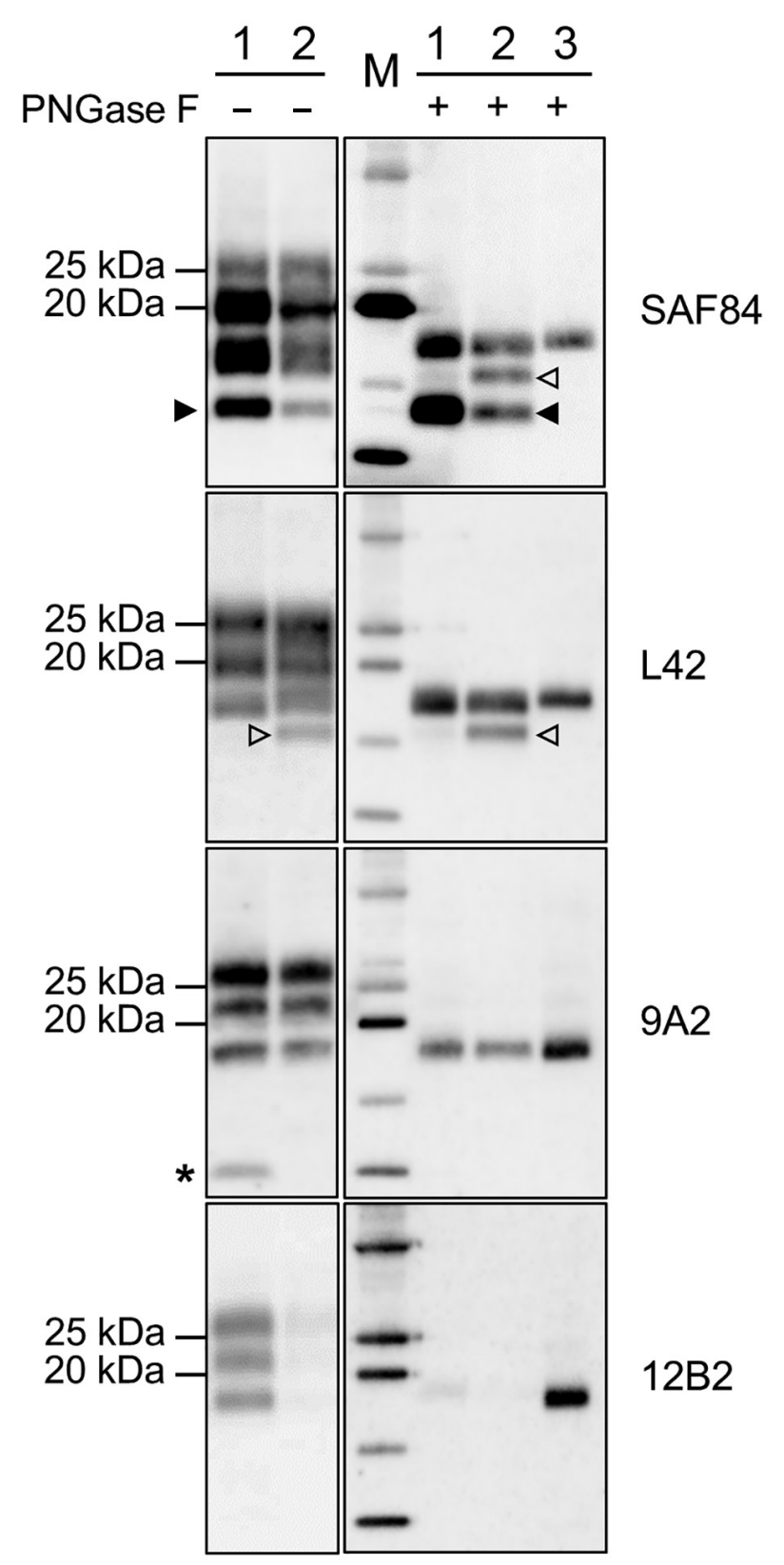

Figure 3. Characterization of PrPres fragments from moose (Alces alces) in Europe by epitope mapping. Mapping with mAbs spanning the whole prion protein enabled the analysis of PrPres in moose samples before (PNGase F-) and after (PNGase F+) deglycosylation, based on presence or absence of the epitopes and apparent molecular weight. Lanes 1, moose no. 1; lanes 2, moose no. 3; lane M, protein standards; lane 3, sheep scrapie sample. Solid arrowheads indicate C-terminal fragment of $\approx 13 \mathrm{kDa}$ fragment (present in both samples and detected with SAF84 mAbs). Open arrowheads indicate C-terminal fragment of $\approx 16 \mathrm{kDa}$ fragment in moose no. 2 with SAF84 and L42 mAbs. Asterisk indicates the internal fragment detected in moose no. 1 with 9A2 mAbs. Molecular weights are indicated on the left. In the blots on the right, protein standards are shown in lane $\mathrm{M}(10,15,20,25$, and $37 \mathrm{kDa})$. The $\mathrm{mAbs}$ used are indicated on the right. mAbs, monoclonal antibodies; PrPres, protease-resistant core of abnormal form of prion protein.
In moose nos. 2 and 3 , an additional glycosylated C-terminal fragment of $\approx 16 \mathrm{kDa}$ (CTF16) was detected by SAF84 and L42 mAbs (Figure 3; online Technical Appendix Figure 2). We cannot exclude that a small amount of CTF16 was also present in moose no. 1 , given that a weak PrPres fragment of $\approx 16 \mathrm{kDa}$ was detectable upon deglycosylation and long exposure of blots (Figure 3; online Technical Appendix Figure 3). Moose nos. 1 and 3 also had a nonglycosylated internal fragment of $\approx 10 \mathrm{kDa}$, cleaved at both $\mathrm{N}$ and $\mathrm{C}$ termini of $\mathrm{PrP}^{\mathrm{Sc}}$, which was recognized by using mAbs $9 \mathrm{~A} 2$ (Figure 3). Moreover, the analysis of PrPres from different neuroanatomic regions showed that the slight differences observed among the 3 moose were not dependent on the area analyzed (online Technical Appendix Figure 2).

\section{Comparison of the PrPsc Features of the Norway Moose with Sheep and Cattle Prion Strains from Europe}

Comparison with ovine and bovine prions was performed to determine the $\mathrm{N}$ terminal cleavage of the main PrP $^{\text {res }}$ fragment by analyzing the different $\mathrm{PrP}^{\mathrm{res}}$ fragments in each sample, the MW of these fragments, and the L42/12B2 antibody ratio (Figure 4; online Technical Appendix Table). Among ovine prions, classical scrapie and atypical/Nor98 were easily discriminated from moose isolates (Figure 5). Classical scrapie $\mathrm{PrP}^{\mathrm{res}}$ had a higher MW than moose PrPres,

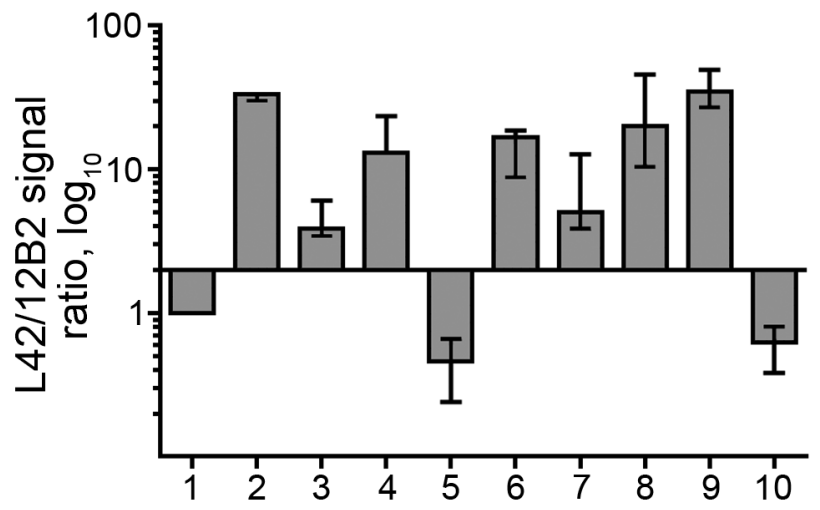

Figure 4. Bar graph of antibody-signal ratios (y-axis) showing discrimination of the ovine, bovine, moose, and reindeer samples (x-axis) analyzed in a study characterizing chronic wasting disease in moose (Alces alces), Norway. Numbers indicate sample type: 1 , scrapie; 2, CH1641; 3, CH1641-like; 4, classical bovine spongiform encephalopathy (BSE); 5, H-type atypical BSE; 6, L-type atypical BSE; 7, moose no. $1 ; 8$, moose no. 2; 9, moose no. 3; 10, reindeer. The antibody ratio is the L42/12B2 ratio of the chemiluminescence signal relative to the L42/12B2 ratio of the control scrapie loaded in each blot. Bars represent median values of $\geq 3$ independent determinations; error bars represent the range of observed values. Bars start at $y=2$, which is the cutoff value of the antibody ratio for the discrimination of low molecular weight samples (i.e., suspected bovine spongiform encephalopathy cases) from scrapie, according to discriminatory Western blot. Numbers indicate sample type: 1 , scrapie; 2, CH1641; 3, CH1641-like; 4, classical bovine spongiform encephalopathy (BSE); 5, H-type atypical BSE; 6, L-type atypical BSE; 7 , moose no. $1 ; 8$, moose no. 2; 9 , moose no. 3 ; 10 , reindeer. 


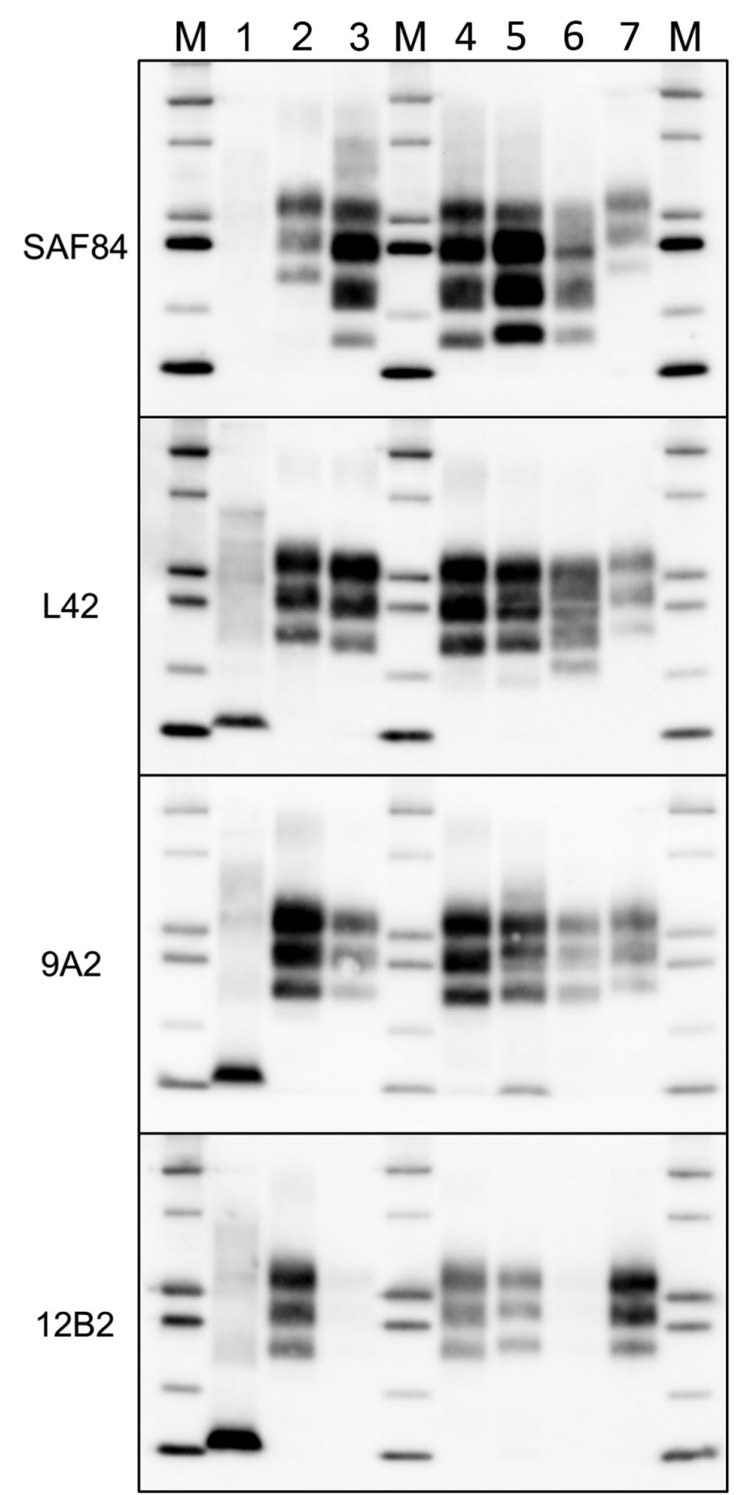

Figure 5. Comparison of protease-resistant PrPres from moose (Alces alces) with chronic wasting disease and from sheep with scrapie, Europe. Representative blots show epitope mapping analysis of PrPres (lane 4, CH1641; lane 5, moose no. 1; lane 6, moose no. 2) in comparison with different ovine transmissible spongiform encephalopathy isolates (lane 1, atypical/Nor98; lane 2, classical scrapie; and lane 3, CH1641). A chronic wasting disease isolate from Canada was loaded as control (lane 7). The antibodies used are indicated on the left. Protein standards are shown in lane $M(10,15,20,25,37$, and $50 \mathrm{kDa})$. The small amount of PrPres with intact 12B2 epitope in moose no. 1 had a molecular weight higher than that observed with more $\mathrm{C}$-terminal monoclonal antibodies $(18.7 \pm 0.3 \mathrm{kDa}$ measured with $12 \mathrm{~B} 2 \mathrm{vs} .17 .2 \pm 0.1 \mathrm{kDa}$ measured with L42). Even if the increase of the apparent molecular weight might be a known behavior when proteinase $\mathrm{K}$ cleavage occurs near the epitope, we noted that, in the case of moose no. 1, the 12B2-positive PrPres had a molecular weight higher than scrapie (18.1 $\pm 0.1 \mathrm{kDa}$ measured with 12B2) and $\mathrm{CH} 1641$-like sample (18.1 $\pm 0.4 \mathrm{kDa}$ when detected with 12B2). PrPres, protease-resistant core of abnormal form of prion protein. as confirmed by the preservation of 12B2 epitope. As previously observed (19), Nor98 PrPres was cleaved at both the N and $\mathrm{C}$ termini, and the characteristic $11-12 \mathrm{kDa}$ band was detected by L42, 9A2, and 12B2 mAbs (Figure 5). In contrast, CH1641 samples showed molecular features partially overlapping with the moose (Figure 5). CH1641 samples showed a $\operatorname{PrP}^{\text {res }}$ of $\approx 17 \mathrm{kDa}$ and were accompanied by an additional C-terminal fragment of 13-14 kDa detected by using SAF84 mAbs (20). However, CTF16 and the internal PrPres fragment of $10 \mathrm{kDa}$ could not be detected in $\mathrm{CH} 1641$ samples.

Moose $\mathrm{PrP}^{\mathrm{Sc}}$ did not overlap with any type of bovine $\mathrm{PrP}^{\mathrm{Sc}}$. The lack of the $12 \mathrm{~B} 2$ epitope in moose $\mathrm{PrP}^{\mathrm{res}}$ was similar to C-type and atypical L-type BSE, but the 2 bovine prions had neither CTF13, CTF16, nor the internal fragment (Figure 6). H-type atypical BSE showed the CTF13 and the internal fragment similar to moose PrPres, but the main $\mathrm{PrP}^{\mathrm{res}}$ fragment showed a higher MW and preserved the 12B2 epitope (Figure 6).

The ratio of reactivity obtained with L42 and 12B2 antibodies reflected the $\mathrm{N}$ terminal cleavage of the main fragment of $\mathrm{PrP}^{\mathrm{Sc}}$, enabling confirmation that the differences observed in MW of PrPres actually depend on different $\mathrm{N}$ terminal proteinase $\mathrm{K}$ cleavages, irrespective of the host species (Figure 4). Values $>2$ are indicative of BSE-like cleavage, whereas values $<1$ indicate a better preservation of 12B2 epitope compared with scrapie. In this respect, the behavior of moose PrPres was BSE-like (ratio $>2$ ). However, moose no. 1 had a ratio lower than moose nos. 2 and 3. The CH1641-like field sample was similar to moose no. 1 in this respect, whereas $\mathrm{CH} 1641$ was similar to moose nos. 2 and 3. Finally, the value $<1$ observed for $\mathrm{PrP}^{\text {res }}$ in H-type atypical BSE, CWD in reindeer, and CWD isolates from Canada reflected their higher MW compared with classical scrapie (online Technical Appendix Table).

\section{Discussion}

Although CWD has been detected in several captive and free-ranging cervid species from a large geographic area in North America, $<10$ cases in moose have been reported (21-23). We report 3 naturally occurring cases of prion disease in moose in Norway that showed molecular and IHC phenotypes differing from those previously described for classical CWD in North America, as well as in reindeer in Norway. The phenomenon of strain variation is well known in prion diseases and is often associated with phenotype variation in natural hosts, as observed in bovines with classical, H-type, or L-type BSE, and in sheep with classical or atypical/Nor98 scrapie. Identification of a new CWD phenotype in 3 moose in Norway can be suggestive of a new CWD strain. Although the existence of CWD strain variation in North America has been inferred from transmission studies (24-26), this phenomenon has not been directly associated with phenotypic variations in natural hosts so far. 
The phenotype variant found in moose from Norway could be hypothetically attributed to host species factors. To address this issue, we directly compared $\mathrm{PrP}^{\mathrm{Sc}}$ characteristics in the Norway moose with those in a Canada moose with CWD. In agreement with the available evidence, we found that the Canada moose $\mathrm{PrP}^{\mathrm{Sc}}$ had

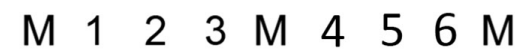

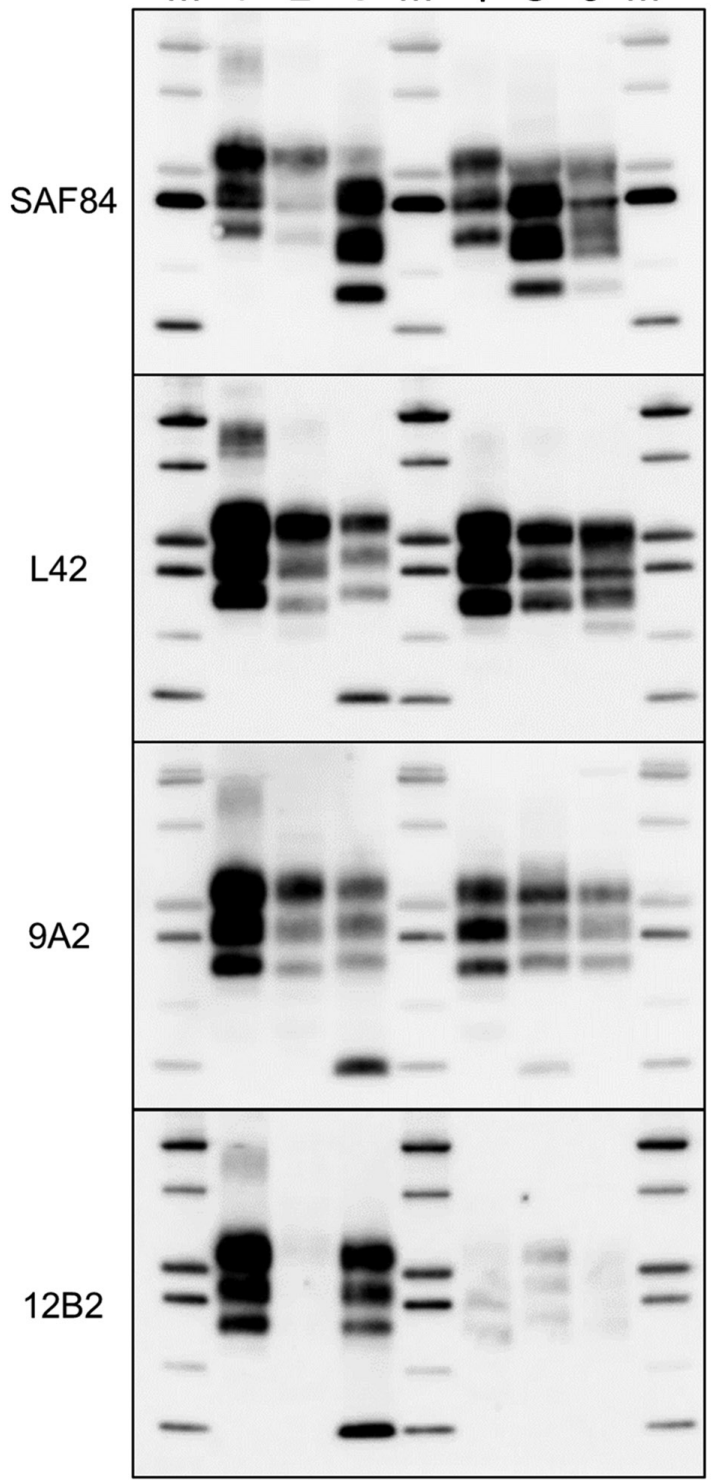

Figure 6. Comparison of protease-resistant core of abnormal form of prion protein from moose (Alces alces) in Europe with chronic wasting disease and from cattle with BSE. Representative blots show epitope mapping analysis of protease-resistant core of abnormal form of prion protein in moose (lane 5, moose no. 1; lane 6, moose no. 2) in comparison with different BSE isolates (lane 2, classical BSE; lane 3, H-type BSE; and lane 4, L-type BSE). A sheep scrapie isolate was loaded as control (lane 1). The antibodies are indicated on the left. Protein standards are shown in lane $M(10,15,20,25,37$, and $50 \mathrm{kDa})$. BSE, bovine spongiform encephalopathy. features different from Norway moose $\mathrm{PrP}^{\mathrm{Sc}}$ and were indistinguishable from other cervids with classical CWD. This finding suggests that the variant $\mathrm{PrP}^{\mathrm{Sc}}$ type observed in Norway moose could not simply reflect a host species factor. Notably, in both natural and experimental conditions, CWD-affected moose in North America have been reported to display disease features indistinguishable from CWD in other cervids and had detectable $\mathrm{PrP}^{\mathrm{Sc}}$ in lymphoid tissues $(21,27)$.

Species-specific amino acid polymorphisms in the cervid PrP are associated with CWD susceptibility, incubation time, and pathology (28-30). In transmission experiments, atypical features were reported in elk or wapiti and mule deer with genotypes associated with a relative resistance to disease, extension of the incubation period, or both $(31,32)$. Moose $\operatorname{PrP}$ is polymorphic at codon $109(\mathrm{~K} / \mathrm{Q})$ and 209 $(\mathrm{M} / \mathrm{I})$, combined in 3 alleles: $\mathrm{K}_{109} \mathrm{M}_{209}$ (observed in Europe and North America), $\mathrm{Q}_{109} \mathrm{M}_{209}$ (observed in Europe), and $\mathrm{K}_{109} \mathrm{I}_{209}$ (observed in North America) $(33,34)$. The 3 moose with CWD from Norway had the $\mathrm{KK}_{109} \mathrm{MM}_{209}$ genotype, whereas the moose case from Canada used for comparison had the $\mathrm{KK}_{109} \mathrm{II}_{209}$ genotype. Thus, we cannot exclude that the differences observed between Norway and Canada moose in our study are dependent on differences in PrP genotype. However, a classical CWD phenotype has been reported in naturally (21) and experimentally infected (27) moose with the $\mathrm{KK}_{100} \mathrm{MM}_{209}$ genotype, suggesting that a difference at PrP codon 209 is probably not the cause of the variant phenotype observed in moose in Norway. All of these findings suggest that neither the species nor the individual PrP genotypes are likely to have caused the variant phenotypes observed and imply that this variant phenotype could represent a novel CWD strain.

CWD is known to be a highly contagious disease in North America; however, data relating to the disease in moose are sparse and insufficient to understand the epidemiology and the implications of CWD in this species. The apparent low CWD prevalence reported for moose in North America compared with other cervid species might be attributable to the individual social behavior of moose and the minimal habitat overlap between moose and other cervids in areas with CWD. Additionally, surveillance program design, disease variability, and host genetics might influence the prevalence of the disease. Based on the epizootic dynamics in North America, CWD plausibly could have become established in reindeer in Norway more than a decade ago (35). In this scenario, the disease in moose could possibly be linked to the disease observed in reindeer, with strain mutation or phenotype shift putatively caused by interspecific transmission. However, a main cause of strain mutation after interspecies transmission (i.e., PrP amino acid differences between the donor and host species) is not relevant in this case because reindeer and moose 
share the same PrP primary sequence. An alternative hypothesis could be that moose have a prion disease that is independent of the reindeer epidemic, being either specific to the Norwegian moose or acquired by species other than the reindeer.

The 3 moose were 13,14, and 13 years of age. Although moose can reach ages beyond 20 years, we consider these moose as old because female moose $>10-12$ years of age start to show signs of senescence and declining survival and reproduction rates $(36,37)$. The old age of the moose, the absence of lymphoid tissue involvement, and the low disease prevalence observed so far ( 3 of 10,531 moose tested) could suggest that CWD in moose is less contagious than classical CWD or could represent a spontaneous TSE. The finding that the affected moose were from the same geographic area does not seem to support a spontaneous origin of the disease; however, the actual evidence for geographic clustering could have been biased by oversampling in Trøndelag County, where the first positive moose was detected. Lack of detailed data on the ages of the moose tested so far in different geographic areas prevents any definitive conclusion. Still, the recent detection of a positive moose in Finland, several hundred kilometers from Trøndelag County, might indicate that the disease is not restricted to Norway (38). The ongoing intensive surveillance in Norway and several European Union countries with large moose populations will help to better clarify the actual geographic distribution and prevalence and will be critical for understanding the contagious or spontaneous nature of the disease.

The 3 moose analyzed shared a distinctive IHC pattern, mainly characterized by intraneuronal accumulation of $\mathrm{PrP}^{\mathrm{Sc}}$, and common $\mathrm{PrP}^{\mathrm{Sc}}$ features, such as the proteinase $\mathrm{K}$ N-terminal cleavage and the presence of an additional CTF13 fragment. However, we also observed unexpected differences among the 3 moose. By WB, the CTF16 fragment was observed in moose nos. 2 and 3 but not in moose no. 1, whereas the nonglycosylated internal fragment of $10 \mathrm{kDa}$ was evident in moose nos. 1 and 3 but could not be detected in moose no. 2. Furthermore, we also showed that these differences did not depend on the brain area investigated. We cannot rule out that these slight differences might depend on technical issues rather than represent actual $\mathrm{PrP}^{\mathrm{Sc}}$ variations. The outcome of the ongoing bioassay experiments will help to clarify the meaning of the observed variations.

By comparing the moose $\operatorname{PrP}^{\mathrm{Sc}}$ features with other animal TSEs circulating in Europe, we found no evidence of similarities with bovine and ovine prions. Minimal similarities were observed with CH1641 samples; however, CH1641 cases have not yet been detected in Norway. Bioassay in a large spectrum of rodent models will assist in determining whether these molecular similarities imply biologic association between the atypical CWD in moose and small ruminant $\mathrm{CH} 1641$. Transmission studies in several rodent models are under way and will help to clarify whether the different phenotype observed (designated Nor$16 \mathrm{CWD}$ ) could reflect the presence of a new cervid prion strain in moose from Norway.

\section{Acknowledgments}

The authors thank the Department of Pathology at the Norwegian Veterinary Institute for their excellent work with TSE testing and sample collection, Liv Midthjell for her skillful PRNP genotyping, Magne Haugum for the necropsy of 2 of the moose, and Jacques Grassi for kindly providing the Norwegian Veterinary Institute with SAF84 mAbs.

This work was supported in part by a grant from the Norwegian Ministry of Agriculture.

\section{About the Author}

Dr. Pirisinu is a researcher at the Istituto Superiore di Sanità in Rome, Italy. Her primary research interests include the prion strain characterization and zoonotic potential of animal prion diseases.

\section{References}

1. Prusiner SB. Molecular biology of prion diseases. Science. 1991;252:1515-22. http://dx.doi.org/10.1126/science.1675487

2. Benestad SL, Telling GC. Chronic wasting disease: an evolving prion disease of cervids. Handb Clin Neurol. 2018;153:135-51. http://dx.doi.org/10.1016/B978-0-444-63945-5.00008-8

3. EFSA Panel on Biological Hazards. Scientific opinion on chronic wasting disease (CWD) in cervids. EFSA J. 2017;15:4667.

4. Kim TY, Shon HJ, Joo YS, Mun UK, Kang KS, Lee YS. Additional cases of Chronic Wasting Disease in imported deer in Korea. J Vet Med Sci. 2005;67:753-9. http://dx.doi.org/10.1292/ jvms. 67.753

5. Miller MW, Swanson HM, Wolfe LL, Quartarone FG, Huwer SL, Southwick CH, et al. Lions and prions and deer demise. PLoS One. 2008;3:e4019. http://dx.doi.org/10.1371/journal.pone.0004019

6. Edmunds DR, Kauffman MJ, Schumaker BA, Lindzey FG, Cook WE, Kreeger TJ, et al. Chronic wasting disease drives population decline of white-tailed deer. PLoS One. 2016; 11:e0161127. http://dx.doi.org/10.1371/journal.pone.0161127

7. Benestad SL, Mitchell G, Simmons M, Ytrehus B, Vikøren T. First case of chronic wasting disease in Europe in a Norwegian free-ranging reindeer. Vet Res (Faisalabad). 2016;47:88. http://dx.doi.org/10.1186/s13567-016-0375-4

8. Rolandsen CM, Solberg EJ, Heim M, Holmstrøm F, Solem MI, Sæther B-E. Accuracy and repeatability of moose (Alces alces) age as estimated from dental cement layers. Eur J Wildl Res. 2008;54:6-14. http://dx.doi.org/10.1007/s10344-007-0100-8

9. Pirisinu L, Migliore S, Di Bari MA, Esposito E, Baron T, D'Agostino C, et al. Molecular discrimination of sheep bovine spongiform encephalopathy from scrapie. Emerg Infect Dis. 2011;17:695-8. http://dx.doi.org/10.3201/eid1704.101215

10. Nicot S, Baron TG. Strain-specific proteolytic processing of the prion protein in prion diseases of ruminants transmitted in ovine transgenic mice. J Gen Virol. 2010;91:570-4. http://dx.doi.org/10.1099/vir.0.014464-0 
11. Kaluz S, Kaluzova M, Flint APF. Sequencing analysis of prion genes from red deer and camel. Gene. 1997;199:283-6. http://dx.doi.org/10.1016/S0378-1119(97)00382-X

12. Community Reference Laboratory of the European Union. TSE strain characterization in small ruminants - a technical handbook for national reference laboratories in the EU. Version 8. December 2016 [cited 2016 Dec 12]. https://science.vla.gov.uk/tse-lab-net/ documents/tse-oie-rl-handbook.pdf

13. Rolandsen CM, Solberg EJ, Saether B-E, Moorter BV, Herfindal I, Bjørneraas K. On fitness and partial migration in a large herbivore - migratory moose have higher reproductive performance than residents. Oikos. 2017;126:547-55. http://dx.doi.org/10.1111/ oik.02996

14. Bunnefeld N, Börger L, van Moorter B, Rolandsen CM, Dettki H, Solberg EJ, et al. A model-driven approach to quantify migration patterns: individual, regional and yearly differences. J Anim Ecol. 2011; 80:466-76. http://dx.doi.org/10.1111/j.1365-2656.2010. 01776.x

15. Meisingset EL, Loe LE, Brekkum Ø, Bischof R, Rivrud IM, Lande US, et al. Spatial mismatch between management units and movement ecology of a partially migratory ungulate. J Appl Ecol. 2018;55:745-53. http://dx.doi.org/10.1111/1365-2664.13003

16. Spraker TR, Miller MW, Williams ES, Getzy DM, Adrian WJ, Schoonveld GG, et al. Spongiform encephalopathy in free-ranging mule deer (Odocoileus hemionus), white-tailed deer (Odocoileus virginianus) and Rocky Mountain elk (Cervus elaphus nelsoni) in northcentral Colorado. J Wildl Dis. 1997;33:1-6. http://dx.doi.org/10.7589/0090-3558-33.1.1

17. Williams ES, Young S. Neuropathology of chronic wasting disease of mule deer (Odocoileus hemionus) and elk (Cervus elaphus nelsoni). Vet Pathol. 1993;30:36-45. http://dx.doi.org/10.1177/ 030098589303000105

18. Spraker TR, Zink RR, Cummings BA, Wild MA, Miller MW, O'Rourke KI. Comparison of histological lesions and immunohistochemical staining of proteinase-resistant prion protein in a naturally occurring spongiform encephalopathy of free-ranging mule deer (Odocoileus hemionus) with those of chronic wasting disease of captive mule deer. Vet Pathol. 2002;39:110-9. http://dx.doi.org/10.1354/vp.39-1-110

19. Pirisinu L, Nonno R, Esposito E, Benestad SL, Gambetti P, Agrimi U, et al. Small ruminant nor98 prions share biochemical features with human gerstmann-sträussler-scheinker disease and variably protease-sensitive prionopathy. PLoS One. 2013;8:e66405. http://dx.doi.org/10.1371/journal.pone.0066405

20. Baron T, Bencsik A, Vulin J, Biacabe AG, Morignat E, Verchere J, et al. A C-terminal protease-resistant prion fragment distinguishes ovine "CH1641-like" scrapie from bovine classical and L-Type BSE in ovine transgenic mice. PLoS Pathog. 2008;4:e1000137. http://dx.doi.org/10.1371/journal.ppat.1000137

21. Baeten LA, Powers BE, Jewell JE, Spraker TR, Miller MW. A natural case of chronic wasting disease in a free-ranging moose (Alces alces shirasi). J Wildl Dis. 2007;43:309-14. http://dx.doi.org/10.7589/0090-3558-43.2.309

22. Moreno JA, Telling GC. Molecular mechanisms of chronic wasting disease prion propagation. Cold Spring Harb Perspect Med. 2018;8:a024448. http://dx.doi.org/10.1101/cshperspect.a024448

23. Haley NJ, Hoover EA. Chronic wasting disease of cervids: current knowledge and future perspectives. Annu Rev Anim Biosci. 2015;3:305-25. http://dx.doi.org/10.1146/annurev-animal022114-111001

24. Raymond GJ, Raymond LD, Meade-White KD, Hughson AG, Favara C, Gardner D, et al. Transmission and adaptation of chronic wasting disease to hamsters and transgenic mice: evidence for strains. J Virol. 2007;81:4305-14. http://dx.doi.org/10.1128/ JVI.02474-06

25. Angers RC, Kang HE, Napier D, Browning S, Seward T, Mathiason $\mathrm{C}$, et al. Prion strain mutation determined by prion protein conformational compatibility and primary structure. Science. 2010;328:1154-8. http://dx.doi.org/10.1126/ science. 1187107

26. Perrott MR, Sigurdson CJ, Mason GL, Hoover EA. Evidence for distinct chronic wasting disease (CWD) strains in experimental CWD in ferrets. J Gen Virol. 2012;93:212-21. http://dx.doi.org/ 10.1099/vir.0.035006-0

27. Kreeger TJ, Montgomery DL, Jewell JE, Schultz W, Williams ES. Oral transmission of chronic wasting disease in captive Shira's moose. J Wildl Dis. 2006;42:640-5. http://dx.doi.org/ 10.7589/0090-3558-42.3.640

28. Jewell JE, Conner MM, Wolfe LL, Miller MW, Williams ES. Low frequency of PrP genotype 225SF among free-ranging mule deer (Odocoileus hemionus) with chronic wasting disease. J Gen Virol. 2005;86:2127-34. http://dx.doi.org/10.1099/ vir. $0.81077-0$

29. Johnson CJ, Herbst A, Duque-Velasquez C, Vanderloo JP, Bochsler P, Chappell R, et al. Prion protein polymorphisms affect chronic wasting disease progression. PLoS One. 2011;6:e17450. http://dx.doi.org/10.1371/journal.pone.0017450

30. Robinson SJ, Samuel MD, O'Rourke KI, Johnson CJ. The role of genetics in chronic wasting disease of North American cervids. Prion. 2012;6:153-62. http://dx.doi.org/10.4161/pri.19640

31. O'Rourke KI, Spraker TR, Zhuang D, Greenlee JJ, Gidlewski TE, Hamir AN. Elk with a long incubation prion disease phenotype have a unique PrPd profile. Neuroreport. 2007;18:1935-8. http://dx.doi.org/10.1097/WNR.0b013e3282f1ca2f

32. Wolfe LL, Fox KA, Miller MW. "Atypical” chronic wasting disease in PRNP genotype 225FF mule deer. J Wildl Dis. 2014;50:660-5. http://dx.doi.org/10.7589/2013-10-274

33. Huson HJ, Happ GM. Polymorphisms of the prion protein gene (PRNP) in Alaskan moose (Alces alces gigas). Anim Genet. 2006; 37:425-6. http://dx.doi.org/10.1111/j.1365-2052.2006.01466.x

34. Wik L, Mikko S, Klingeborn M, Stéen M, Simonsson M, Linné T. Polymorphisms and variants in the prion protein sequence of European moose (Alces alces), reindeer (Rangifer tarandus), roe deer (Capreolus capreolus) and fallow deer (Dama dama) in Scandinavia. Prion. 2012;6:256-60. http://dx.doi.org/10.4161/ pri. 19641

35. EFSA Panel on Biological Hazards. Scientific opinion on chronic wasting disease (II). EFSA J. 2018;16:5132.

36. Ericsson G, Wallin K. Age-specific moose (Alces alces) mortality in a predator-free environment: evidence for senescence in females. Ecoscience. 2001;8:157-63. http://dx.doi.org/10.1080/11956860.20 01.11682641

37. Ericsson G, Wallin K, Ball JP, Broberg M. Age-related reproductive effort and senescence in free-ranging moose, Alces alces. Ecology. 2001;82:1613. http://dx.doi.org/10.2307/2679804

38. Finnish Food Safety Authority (Evira). Moose found dead in forest with chronic wasting disease [cited $2018 \mathrm{Mar} 8$ ]. https://www.evira.fi/en/animals/current_issues/2018/moose-founddead-in-forest-with-chronic-wasting-disease

Address for correspondence: Sylvie L. Benestad, Norwegian Veterinary Institute, Pathology, PO Box 750 Sentrum, 0106 Oslo, Norway; email: sylvie.benestad@vetinst.no 